\title{
Comparative Study of Cancer Treatment Potential Effects of Tumor-Treating Fields and Cold Atmospheric Plasma
}

\author{
Xiaoliang Yao, ${ }^{a}$ Isaac Goldstein, ${ }^{\mathrm{b}}$ Li Lin, ${ }^{\text {a }}$ Jonathan H. Sherman, ${ }^{\text {a }}$ \& \\ Michael Keidara,* \\ aThe George Washington University, Washington, DC 20052; ' University of California at \\ Berkeley, Berkeley, California 94720 \\ *Address all correspondence to: Michael Keidar, 800 22nd Street, NW, Washington, DC 20052; Tel./Fax: +202-994- \\ 6080, E-mail: keidar@gwu.edu
}

\begin{abstract}
Tumor-treating fields (TTFields) therapy is well known and approved by the Food and Drug Administration for treatment of adult patients who suffer with glioblastoma. The method uses low-intensity and intermediate-frequency alternating electric fields to produce an inhibitory effect on cancerous cells. However, it involves $24 \mathrm{~h}$ of treatment time to produce anticancer effects. A new modality of cancer treatment called cold plasma therapy (CPT) has been shown both in vitro and in mice models to significantly treat dozens of cancer types. CPT is based on the therapeutic effect of cold atmospheric plasma (CAP), a type of ionized gas that operates at close to room temperature and provides electromagnetic radiation as well as reactive oxygen and nitrogen species, both cytotoxic to cancer cells. With this study, after investigating the anticancer effects of TTFields and CAP on glioblastoma cells, we have found that CAP has superior ability to inhibit cancer.
\end{abstract}

KEY WORDS: plasma

\section{INTRODUCTION}

Cancer is the second most common cause of death in the United States (US). In 2017, 688,780 new cancer cases were diagnosed, and 600,920 cancer-related deaths occurred in the US. ${ }^{1}$ We have identified $>100$ types of cancers such as those occurring in lung, skin, and brain. ${ }^{2-4}$ Several methods of cancer treatment exist ${ }^{5}$ including surgery, chemotherapy, radiation therapy, and immunotherapy. Some relatively recent innovations in the field of cancer treatment have been developed, such as the use of cold atmospheric plasma (CAP) to kill cancer cells by creation of electromagnetic waves and reactive oxygen and nitrogen species. ${ }^{6-9}$ Current research has shown that electric fields at $200-300 \mathrm{MHz}$ frequency can act to rapidly divide cells of cancerous tumors. ${ }^{10} \mathrm{In}$ this study, we performed a comparative review to evaluate the effects of tumor-treating fields (TTFields) and CAP treatment on glioblastoma.

Plasma is the fourth state of matter, essentially consisting of ionized gas with electrons, ions, and uncharged particles. The two kinds of plasma are thermal and nonthermal. Thermal plasma contains electrons and gas at approximately the same temperatures, whereas electrons in nonthermal plasma exist at a much higher temperature than that of heavy particles. The nonthermal plasma that we used for this experiment is CAP, so 
called because it is not significantly warmer than room temperature. ${ }^{11-13} \mathrm{CAP}$ is popular in the medical field for use in applications such as antibacterial treatment and wound healing. ${ }^{14}$ Research has also been performed on the use of CAP as a potential cancer therapy. ${ }^{15-17}$ A variety of gases can be used to generate CAP, including air, argon, helium, and nitrogen. Additionally, multiple methods produce CAP, such as dielectric barrier discharge and atmospheric pressure plasma jet. ${ }^{18}$ During the last decade, CAP has become extremely promising as an application for cancer treatment due to its selectivity for cancer cells, as seen in in vivo applications. ${ }^{19-23}$

TTFields therapy uses a low-intensity and intermediate-frequency electric field that can inhibit cancer cell growth. ${ }^{24}$ Research has shown that by using implanted electrodes, TTFields successfully inhibited tumor growth in mice. ${ }^{24}$ Electric activity plays a vital part in this biological process. Electric fields, ranging mostly between 0 and $20 \mathrm{~V} / \mathrm{cm}$, stimulate ion flow and cause polar molecules to orient themselves along lines following the uniform field. However, nonuniform fields affect polar forces that may allow movement to increased field intensity. ${ }^{25}$ The mechanism by which TTFields affects cells occurs when field frequency reaches between $100 \mathrm{kHz}$ and $1 \mathrm{MHz}$, at which point it can act on dividing cells. This manifests through a disruption of spindle tubulin orientation during cytokinesis, inducing dielectrophoresis. The TTFields approach requires lengthy treatment of at least $24 \mathrm{~h} .{ }^{26}$ In contrast, on the basis of in vivo preclinical data, the CAP approach generally requires only several minutes of treatment. ${ }^{27}$ In this study, we examined both approaches, CAP and TTFields, and determined the comparative efficacy of both techniques.

\section{EXPERIMENT AND METHOD}

\section{A. TTFields Device Setup}

Figure 1 shows the device that we used for the TTFields experimental setup. The size of the plate was the same as a 24-well culture plate: $127 \mathrm{~mm}$ long, $85 \mathrm{~mm}$ wide, and $20 \mathrm{~mm}$ high. The lid contained 48 electrodes (two electrodes in each well, at a distance of $1 \mathrm{~cm}$ ). The surface for each well was $2 \mathrm{~cm}^{2}$. In each well, we placed two electrodes made of gold and

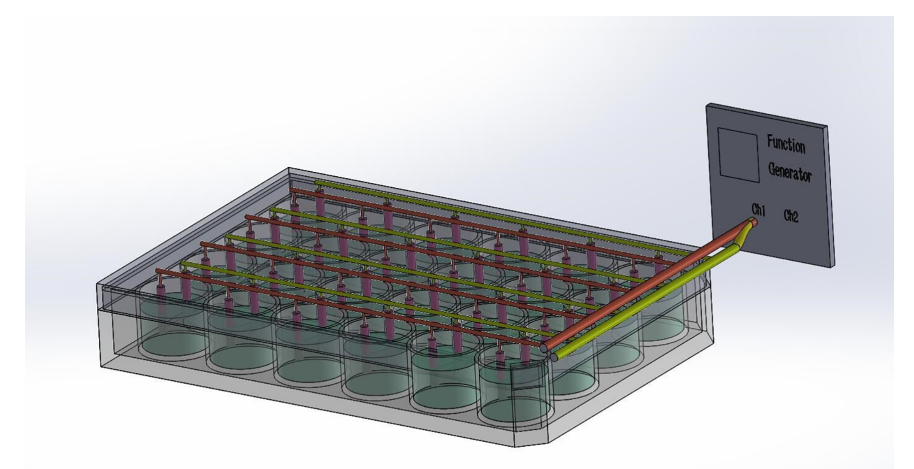

FIG. 1: Schematic of TTFields device setup based on a 24-well cell culture plate 
measuring 0.377 in long and 0.08 in in diameter to produce TTFields that were controlled by a power supply. At the first and second row of each plate, frequency and intensity were controlled by changing power-supply settings. The plate's third and fourth rows were used as a control (they were not connected to the power supply and thus did not produce TTFields).

\section{B. CAP Setup}

The CAP jet in this experiment was designed and assembled in a micropropulsion and nanotechnology laboratory (Fig. 2). ${ }^{6}$ The jet used helium as the carrying gas to trigger the discharge process and form CAP with a flow rate of $8 \mathrm{~L} / \mathrm{min}$. Electrodes were connected to a high-voltage resonant transformer (Chirk Industry Co. Ltd., Taoyuan, Taiwan) (8 kV peak to peak; frequency $12.5 \mathrm{kHz})$.

\section{Cell Cultures}

For this experiment, we used cell line U87, a human primary glioblastoma line. Cell cultures were grown in high-glucose Dulbecco's Modified Eagle's Medium (DMEM, with L-glutamine), supplemented with $10 \%$ (v/v) fetal bovine serum and $1 \%$ penicillin-streptomycin solution media in a $5 \% \mathrm{CO}_{2}$ incubator at $37^{\circ} \mathrm{C}$. We placed $2 \mathrm{~mL}$ of cells in each well (a total of 18,000 cells per well) of the 24-well plate and incubated the cells for $24 \mathrm{~h}$.

\section{Optical Emission Spectroscopy}

In this experiment, we fixed the wavelength range to $191-851.5 \mathrm{~nm}$ and set the CAP jet to a calculated intensity ratio of 391.4:337.1 $\mathrm{nm}$. The spectroscopy meter and optical

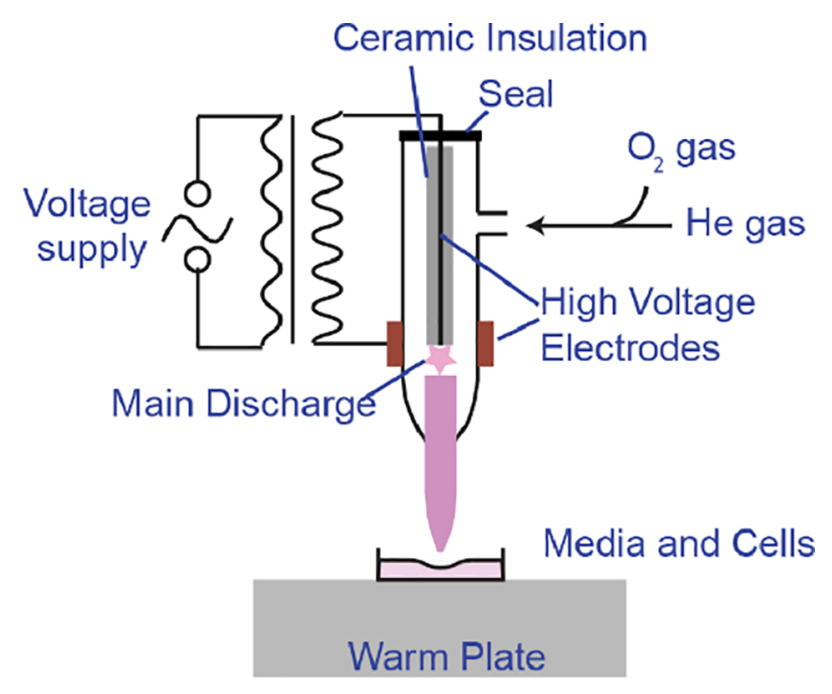

FIG. 2: Schematic of CAP device setup 
probe were purchased from StellarNet Inc. (Tampa, FL). We set the optical probe to 5 $\mathrm{cm}$ below and $2.5 \mathrm{~cm}$ in front of the nozzle.

\section{E. Ansys Fluent Software}

We used Ansys Fluent software (Ansys, Inc., Canonsburg, PA) to simulate CAP composition of each species $\left(\mathrm{N}_{2}, \mathrm{O}_{2}, \mathrm{He}\right.$, and $\left.\mathrm{H}_{2} \mathrm{O}\right)$ at the tip of the plasma jet. For this, we assumed the inlet to be al helium. Therefore, the composition of helium was $100 \%$ at the inlet, and other gas species were at $0 \%$. Distance from the 24 -well culture plate from table to floor was $1.2 \mathrm{~m}$, and the distance from tube to plate was $5 \mathrm{~cm}$. The composition of each species in air was $78.09 \%$ nitrogen, $20.95 \%$ oxygen, $0.04 \%$ carbon dioxide, $0.0005 \%$ helium, and $0.92 \%$ other gases. The molar mass for nitrogen was $28.01 \mathrm{~g} / \mathrm{mol}$, and that for oxygen $31.99 \mathrm{~g} / \mathrm{mol}$, carbon dioxide $44.01 \mathrm{~g} / \mathrm{mol}$, and helium $4 \mathrm{~g} / \mathrm{mol}$.

\section{F. Cell Viability Assay}

Cell viability was measured using a 3-(4,5-dimethylthiazol-2-yl)-2,5-diphenyltetrazolium bromide (thiazolyl blue tetrazolium blue [MTT]) assay (Sigma-Aldrich Inc., St. Louis, MO). MTT is a colorimetric assay that is used to measure cell metabolic activity and reflects the number of viable cells. In living cells, it reduces cellular enzymes to formazan, giving them a purple color. We cultured cells in an incubator for $72 \mathrm{~h}$ after the TTFields and CAP experiment. After $72 \mathrm{~h}$, we aspirated the DMEM from each well and added $300 \mu \mathrm{L}$ MTT solution ( $7 \mathrm{mg}$ MTT in $10 \mathrm{~mL}$ of medium for one plate) to each well. Cells were then incubated for another $3 \mathrm{~h}$ to produce the MTT reaction. We followed by aspirating the MTT and adding another $300 \mu \mathrm{L}$ of MTT solvent $(0.4 \%[\mathrm{v} / \mathrm{v}] \mathrm{HCl}$ in anhydrous isopropanol) to each well to dissolve the crystals that formed from the reaction. Each plate was then measured using the Synergy H1 hybrid multimode microplate reader (BioTek Instruments Inc., Winooski, VT) with a frequency of $570 \mathrm{~nm}$.

\section{G. Statistical Analysis}

The results were plotted using Microsoft Excel as mean \pm standard deviation. We used the student $t$-test to check for a statistical significance of $p<0.05$.

\section{POWER CALCULATION}

\section{A. Power Delivered to Cells with CAP Treatment}

The calculation of plasma power was based on a Joule heat estimation (Eq. [1]) that requires calculation of the current near the DMEM-cell target and the impedance of DMEM with cells, as follows:

$$
P=Z I^{2},
$$


where $P$ is power delivered to cells, $Z$ is impedance, and $I$ is current. We measured current at the plasma jet tip using a Rogowski coil, and found $I$ to be $\sim 0.15$ A. Plasma impedance was calculated as

$$
Z=\frac{1}{\sigma}
$$

where is the conductivity that can be calculated as

$$
I / A=\sigma E
$$

Here, $I$ and $A$ are current at the plasma jet tip and cross-area of the tip, respectfully, and $E$ is local electric field. The cross-area of the plasma jet was $\sim 3.5 \mathrm{~mm}^{2}$. Electric field can be estimated from the optical emission spectrum (OES). Here, we used the ratio of intensities, following Yan et al. ${ }^{28}$ and found

$$
R_{I_{391} / I_{337}}\left(U_{d i s}\right)=5.4938 \times R_{k_{391} / k_{337}}\left(T_{e}\right)
$$

where $R_{I_{391} / I_{337}}$ is the intensity ratio of $391 / 337 \mathrm{~nm}$ measured at the tip of the helium cold plasma jet, and $R_{k_{391} / k_{337}}(T)$ is the ratio of the rate of coefficients of electron impact excitations. Reduced electric field can be estimated based on ratio of intensities versus rate of coefficients, generated from Eq. (4). ${ }^{28}$ Let us consider the OES of the helium CAP jet interacting with ambient air, having a flow rate of $\sim 4.7 \mathrm{~L} / \mathrm{min}$ and sinusoidal discharge voltage of $\sim 8 \mathrm{kV}$ peak to peak at $12.5 \mathrm{kHz}$ frequency. The intensity ratio of $391 / 337 \mathrm{~nm}$ is 0.49 . Therefore, the value of $R_{k_{391} / k_{337}}\left(T_{e}\right)$ was calculated to be 0.087 . The relationship between $R_{k_{391} / k_{337}}$ and $E / N$ can be found from the Boltzmann solver BOLSIG+, based on a fluid simulation of helium jet in air using three-dimensional (3D) ANSYS Fluent (details are discussed in Appendix B). ${ }^{29}$ As a result of this analysis, $E$ was estimated as $1.37 \times 10^{4} \mathrm{kV} / \mathrm{m}$, and $\sigma \sim 0.0035 \Omega^{-1} \mathrm{~m}^{2}$. Therefore, the power in the plasma jet tip was $\sim 6.43 \mathrm{~W}$. However, the plasma discharge period is $80 \mu \mathrm{s}$, and the streamer propagation takes only $\sim 2 \mu \mathrm{s}$. We assume that plasma energy was only delivered to the cells during the streamer propagation period. Therefore, the actual power of the plasma jet was calculated to be $6.43 \mathrm{~W} \times(2 \mu \mathrm{s} / 80 \mu \mathrm{s})=0.16 \mathrm{~W}^{30}$

\section{B. Power Delivered to Cells with TTFields Treatment}

Because the frequency of TTFields is constant, the power delivered to cells was estimated as

$$
P=\frac{U^{2}}{Z}
$$


where $U$ is the voltage applied between the two electrodes, $Z$ is the impedance of DMEM with cells (measured to be $330 \Omega$ ), and frequency was $\sim 300 \mathrm{kHz}$.

\section{RESULTS AND DISCUSSIONS}

\section{A. TTFields Treatment}

Five voltage levels $(2,4,10,15$, and $19 \mathrm{~V})$ were chosen to treat the U87 cells that were cultured in 24-well plates. Treatment time was universally kept at $\sim 4 \mathrm{~h}$. Calculated energy that was delivered to cells from TTFields is shown in Fig. 3. MTT assay results show the effects of TTFields on cell viability, shown in Fig. 4(A). All cell viability data were normalized relative to the control. Figure 4(A) demonstrates that higher voltage leads to decreased cell viability and the increasingly greater effect of TTFields. This suggests that electromagnetic field generated by TTFields contributes to the death of U87 cancer cells. Therefore, we conclude that the power of TTFields contributes significantly to U87 cancer cell death, shown in Fig. 4(A). As such, in all experiments, maximum voltage that we used was $19 \mathrm{~V}$ to avoid the negative effect of high temperature caused by higher voltage.

We also tested the effect of TTFields treatment duration on cell viability by keeping TTFields voltage constant. Treatments were performed for 1, 2, 3, and $4 \mathrm{~h}$ while voltage was held constant at $\sim 19 \mathrm{~V}$, as shown in Fig. 4(B). Total energy calculated for TTFields is also shown. All viability data were normalized relative to the control. The

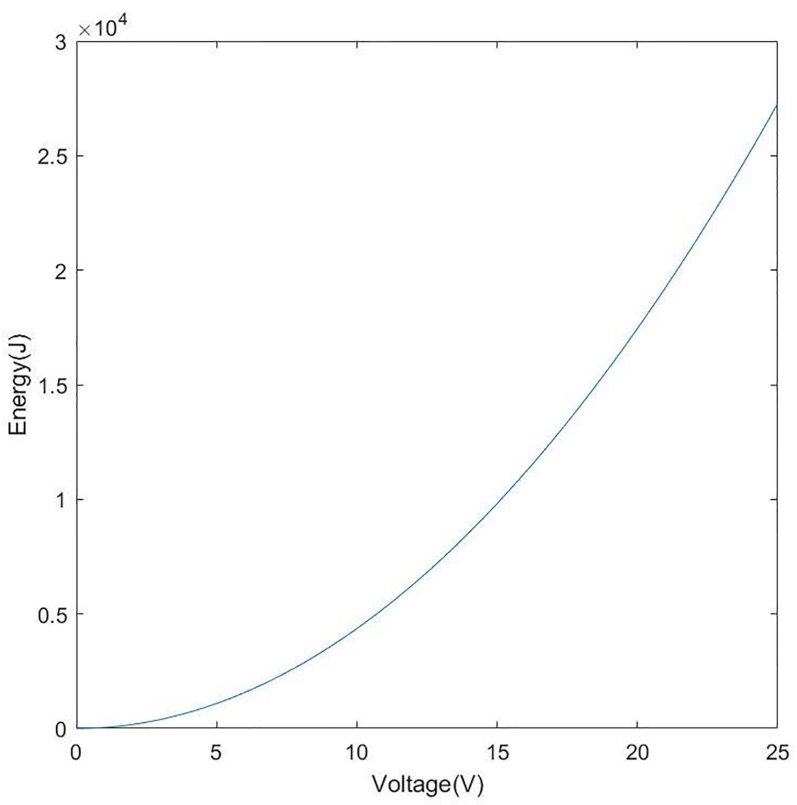

FIG. 3: Energy delivered to cells by TTFields during $4 \mathrm{~h}$ 


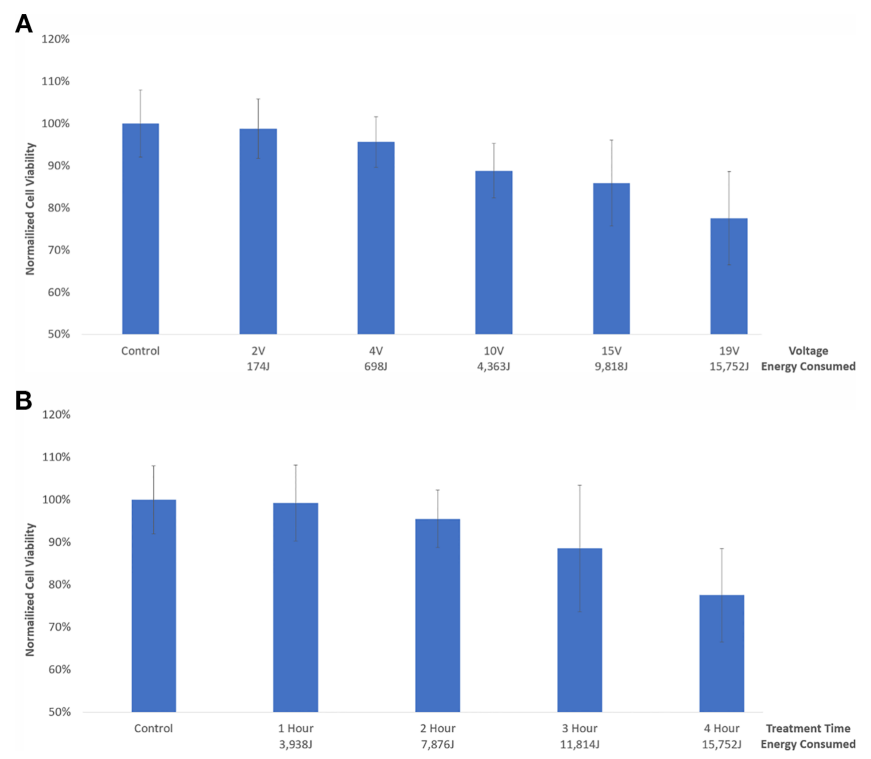

FIG. 4: (A) Cell viability dependence on applied voltage and calculated energy input. U87 cells were treated for $4 \mathrm{~h}, 18,000$ cells. (B) Cell viability dependence treatment time with constant voltage $(19 \mathrm{~V})$.

experiment of the MTT assay shows that increasing the time of TTFields treatment also increases efficacy (Fig. 4[B]). While TTFields energy remained constant, the increased treatment time that was applied to the cancer cells increased efficacy (decreased cell viability).

\section{B. CAP Treatment}

We treated U87 cells with CAP for 30,60, and $90 \mathrm{~s}$ at room temperature and performed MTT assays $72 \mathrm{~h}$ after treatment. All viability data were normalized relative to control. We calculated energy delivered to cells during CAP treatment on the basis of the OES peak ratio, gas composition, and current in the CAP jet. Details of these calculations can be found in Appendix A. Results of the MTT assay showed that CAP affects cell viability in a time-dependent manner and the addition of energy leads to increased CAP effect on cells. Cell viability decreased by $48 \%$ after $9.6 \mathrm{~J}$ was applied to the cell, compared to a decrease of $71.7 \%$ after $24 \mathrm{~J}$ was applied.

After investigating the anticancer effect of TTFields and CAP on glioblastoma cells, we found CAP had a superior ability to inhibit cancer. As shown in Figs. 4(a) and (b) and Fig. 5, treatment time for TTFields needed to be $4 \mathrm{~h}$, compared with CAP, which only requires $30 \mathrm{~s}$ to produce the same cell viability value. Moreover, CAP is significantly energy efficient. As shown in Figs. 4 and 5, energy required for an $80 \%$ cell viability value of TTFields is $\sim 15.7 \mathrm{~kJ}$ or $>3000$ times that of CAP, which requires $\sim 5 \mathrm{~J}$. 


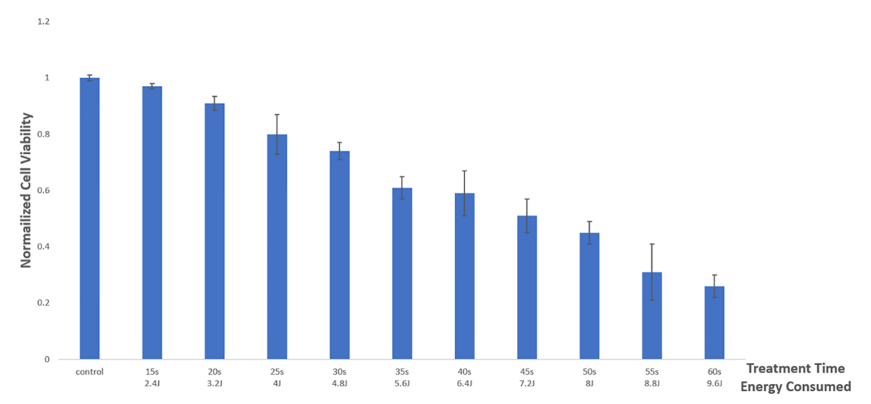

FIG. 5: Cell viability dependence on CAP treatment time and association with energy delivered by CAP jet to cells

\section{CONCLUSIONS}

In this study, we directly compared CAP and TTFields treatment of U87 glioblastoma cancer cells. We aimed to assess the relative merits of two technologies as potential approaches for cancer treatment. The energy that we applied varied for both methods, and resulting cell viability changes were measured. For the two methods, we demonstrated that increased use of energy resulted in decreased cell viability for cancer cells. Results indicated that the rate of cancer cell viability using CAP treatment was $80 \%$ of the original viability after using $4.8 \mathrm{~J}$, compared with TTFields treatment that required $15.7 \mathrm{~kJ}$. This data indicate that CAP is significantly more energy efficient. In addition, CAP treatment was completed in $30 \mathrm{~s}$, whereas the most effective TTFields treatment took $4 \mathrm{~h}$, indicating that CAP treatment is a more favorable and effective method for cancer therapy.

\section{ACKNOWLEDGMENTS}

This work was supported by the National Science Foundation (Grant No. 1747760). We also thank Dr. Dayun Yan and Vikas Soni for helpful discussions and support.

\section{REFERENCES}

1. Siegel RL, Miller KD, Jemal A. Cancer statistics, 2020. CA Cancer J Clin. 2020 Jan;70(1):7-30.

2. Weinberg RA. How cancer arises. Sci Am. 1996 Sep 1;275(3):62-70.

3. Wang M, Holmes B, Cheng X, Zhu W, Keidar M, Zhang LG. Cold atmospheric plasma for selectively ablating metastatic breast cancer cells. PLoS One. 2013;8(9):e73741.

4. Minniti G, Filippi AR, Osti MF, Ricardi U. Radiation therapy for older patients with brain tumors. Radiat Oncol. 2017 Dec 1;12(1):101.

5. Vanneman M, Dranoff G. Combining immunotherapy and targeted therapies in cancer treatment. Nat Rev Cancer. 2012 Apr;12(4):237-51.

6. Cheng X, Sherman J, Murphy W, Ratovitski E, Canady J, Keidar M. The effect of tuning cold plasma composition on glioblastoma cell viability. PLoS One. 2014;9(5):e98652.

7. Yan D, Talbot A, Nourmohammadi N, Cheng X, Canady J, Sherman J, Keidar M. Principles of using cold atmospheric plasma stimulated media for cancer treatment. Sci Rep. 2015 Dec 17;5:18339. 
8. Keidar M. Plasma for cancer treatment. Plasma Sources Sci Technol. 2015 May 20;24(3):033001.

9. Ratovitski EA, Cheng X, Yan D, Sherman JH, Canady J, Trink B, Keidar M. Anti-cancer therapies of 21st century: novel approach to treat human cancers using cold atmospheric plasma. Plasma Proc Polymers. 2014 Dec;11(12):1128-37.

10. Stupp R, Taillibert S, Kanner A, Read W, Steinberg DM, Lhermitte B, Toms S, Idbaih A, Ahluwalia MS, Fink K, Di Meco F. Effect of tumor-treating fields plus maintenance temozolomide vs. maintenance temozolomide alone on survival in patients with glioblastoma: A randomized clinical trial. JAMA. 2017 Dec 19;318(23):2306-16.

11. Tanaka H, Mizuno M, Ishikawa K, Takeda K, Nakamura K, Utsumi F, Kajiyama H, Kano H, Okazaki Y, Toyokuni S, Maruyama S. Plasma medical science for cancer therapy: Toward cancer therapy using nonthermal atmospheric pressure plasma. IEEE Trans Plasma Sci. 2014 Nov 13;42(12):3760-4.

12. Samal S. Thermal plasma technology: The prospective future in material processing. J Clean Prod. 2017 Jan 20;142:3131-50.

13. Haertel B, Von Woedtke T, Weltmann KD, Lindequist U. Non-thermal atmospheric-pressure plasma possible application in wound healing. Biomol Ther. 2014 Nov;22(6):477.

14. Arndt S, Unger P, Wacker E, Shimizu T, Heinlin J, Li YF, Thomas HM, Morfill GE, Zimmermann JL, Bosserhoff AK, Karrer S. Cold atmospheric plasma (CAP) changes gene expression of key molecules of the wound healing machinery and improves wound healing in vitro and in vivo. PLoS One. 2013;8(11):e79325.

15. Tanaka H, Mizuno M, Ishikawa K, Takeda K, Nakamura K, Utsumi F, Kajiyama H, Kano H, Okazaki Y, Toyokuni S, Maruyama S. Plasma medical science for cancer therapy: Toward cancer therapy using nonthermal atmospheric pressure plasma. IEEE Trans Plasma Sci. 2014 Nov 13;42(12):3760-4.

16. Keidar M, Yan D, Beilis II, Trink B, Sherman JH. Plasmas for treating cancer: Opportunities for adaptive and self-adaptive approaches. Trends Biotechnol. 2018 Jun 1;36(6):586-93.

17. Volotskova O, Hawley TS, Stepp MA, Keidar M. Targeting the cancer cell cycle by cold atmospheric plasma. Sci Rep. 2012 Sep 6;2:636.

18. Laroussi M, Lu X, Keidar M. Perspective: The physics, diagnostics, and applications of atmospheric pressure low temperature plasma sources used in plasma medicine. J Appl Phys. 2017 Jul 14;122(2):020901.

19. Graves DB. Reactive species from cold atmospheric plasma: Implications for cancer therapy. Plasma Proc Polymers. 2014 Dec;11(12):1120-7.

20. Yan D, Talbot A, Nourmohammadi N, Sherman JH, Cheng X, Keidar M. Toward understanding the selective anticancer capacity of cold atmospheric plasma - a model based on aquaporins. Biointerphases. 2015 Dec 22;10(4):040801.

21. Babington P, Rajjoub K, Canady J, Siu A, Keidar M, Sherman JH. Use of cold atmospheric plasma in the treatment of cancer. Biointerphases. 2015 Jun 19;10(2):029403.

22. Keidar M. A prospectus on innovations in the plasma treatment of cancer. Phys Plasmas. 2018 Aug 8;25(8):083504.

23. Keidar M, Yan D, Sherman JH. Cold plasma cancer therapy. San Rafael, CA: Morgan \& Claypool Publ.; 2019.

24. Kirson ED, Dbalý V, Tovaryš F, Vymazal J, Soustiel JF, Itzhaki A, Mordechovich D, Steinberg-Shapira S, Gurvich Z, Schneiderman R, Wasserman Y. Alternating electric fields arrest cell proliferation in animal tumor models and human brain tumors. Proc Natl Acad Sci. 2007 Jun 12;104(24):10152-7.

25. Clague DS, Wheeler EK. Dielectrophoretic manipulation of macromolecules: The electric field. Phys Rev E. 2001 Jul 18;64(2):026605.

26. Kirson ED, Schneiderman RS, Dbalý V, Tovaryš F, Vymazal J, Itzhaki A, Mordechovich D, Gurvich Z, Shmueli E, Goldsher D, Wasserman Y. Chemotherapeutic treatment efficacy and sensitivity are increased by adjuvant alternating electric fields (TTFields). BMC Med Phys. 2009 Dec;9(1):1.

27. Aleinik A, Baikov A, Shevtsova N, Semichev E, Bushlanov P, Turgunova N. Application of cold plasma for performing a typical resection of the spleen. Biomed Phys Eng Expr. 2018 Aug 31;4(5):055026.

Volume 10, Issue 1, 2020 
28. Yan D, Lin L, Xu W, Nourmohammadi N, Sherman JH, Keidar M. Cold plasma-based control of the activation of pancreatic adenocarcinoma cells. J Phys D Appl Phys. 2019 Aug 14;52(44):445202.

29. Hagelaar GJ, Pitchford LC. Solving the Boltzmann equation to obtain electron transport coefficients and rate coefficients for fluid models. Plasma Sources Sci Technol. 2005 Oct 5;14(4):722.

30. Keidar M, Shashurin A, Volotskova O, Ann Stepp M, Srinivasan P, Sandler A, Trink B. Cold atmospheric plasma in cancer therapy. Phys Plasmas. 2013 May 15;20(5):057101.

31. Rumble JR. CRC Handbook of chemistry and physics. London, UK: Taylor \& Francis; 2017.

32. Zhu S, Wang J, Xie B, Luo Z, Lin X, Liao DJ. Culture at a higher temperature mildly inhibits cancer cell growth but enhances chemotherapeutic effects by inhibiting cell-cell collaboration. PLoS One. 2015;10(10):e0137042.

\section{APPENDIX A. 24-WELL PLATE UNIFORMITY}

Despite adding the same number of cells to each well, it was possible that cell numbers in distinct wells at the edges of the plate might differ as a result of the edge effect. We checked the impact of the edge effect by comparing cell numbers at different positions of the plate. In this experiment, we added 12,000 cells to each well of the plate, and cells were then incubated for $96 \mathrm{~h}$. The advantage of cultivation for $96 \mathrm{~h}$ is that this is approximately the same amount of time as the total time that cells were incubated. Normally, cells are already incubated for $24 \mathrm{~h}$ before the experiment begins, then incubated for another $72 \mathrm{~h}$ after the experiment is finished. Figures A1 and A2 show the result for testing the edge effect in the 24-well plate. Figure A1 shows the edge effect check for different rows and Fig. A2 for different layers. Analysis of the data led to the conclusion that the edge effect did not significantly affect this experiment, meaning that if cells have been incubated without any treatment, cell numbers would be at the same level.

\section{APPENDIX B. RELATIONSHIP BETWEEN $R_{k_{391} / k_{337}}$ AND E/N}

The relationship between $R_{k_{391} / k_{337}}$ and $E / N$ could be found by using the Boltzmann solver BOLSIG + , based on a fluid simulation of helium jet in air using 3D ANSYS

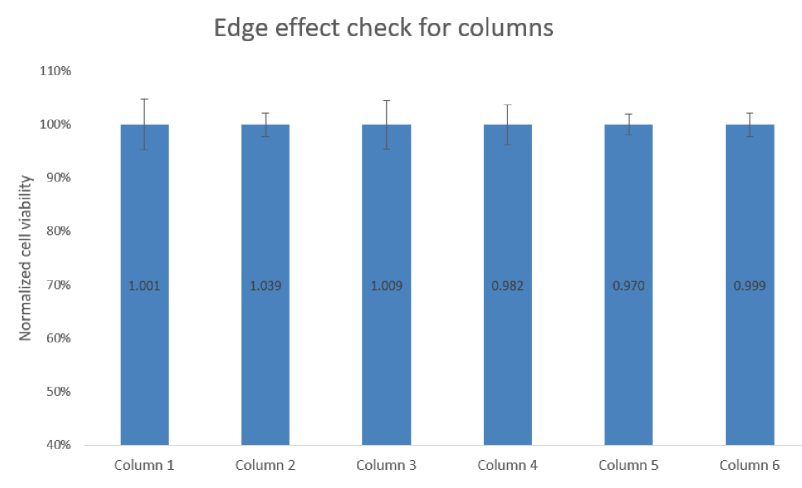

FIG. A1: Cell viability check at different columns for edge effect 


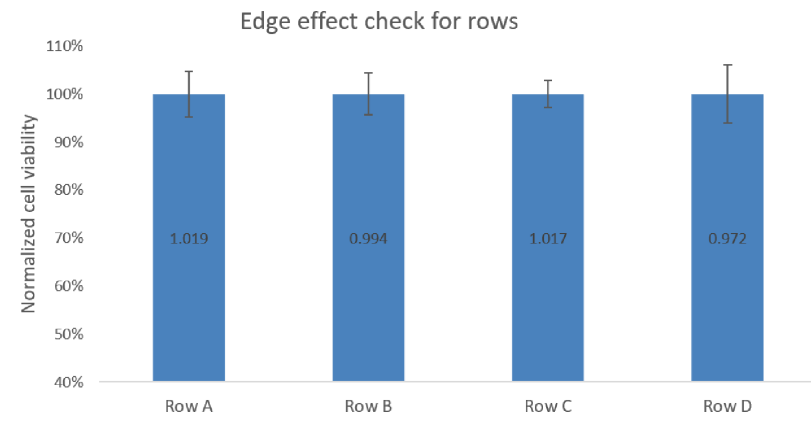

FIG. A2: Cell viability check at different rows for edge effect

Fluent. BOLSIG+ required gas composition of each species at the tip of the plasma jet. Therefore, 3D ANSYS Fluent was used to simulate gas composition at the tip of the plasma jet, as shown in Fig. B1. The location used to estimate the CAP jet composition was $\sim 5 \mathrm{~cm}$ under the plasma nozzle, which is also the center of the plate. The simulated CAP jet was assumed to be $100 \%$ helium at the inlet, with the other gas species at $0 \%$. At $\sim 5 \mathrm{~cm}$, we calculated the volume ratio for nitrogen at $78.08 \%$, oxygen at $20.95 \%$, carbon dioxide at $0.03 \%$, and helium at $0.0005 \%$, as shown in Table B1. It is necessary to mention that a steady state was achieved $\sim 100$ $\mathrm{s}$ after starting simulations (Fig. B1). This result also explains the reason why a great number of researchers found that the CAP was unstable during the first 2 min after it starts (Fig. B2). Results of CAP jet gas composition at a steady state are shown in Table B1.

$R_{I_{391} / I_{337}}\left(U_{d i s}\right)$, the intensity ratio of $391 \mathrm{~nm}$ over $337 \mathrm{~nm}$, was measured from the OES at the tip of the helium cold plasma jet (Fig. B3) to be 0.48 . We calculated $R_{k_{391} / k_{337}}\left(T_{e}\right)$ to be 0.087 based on Eq. (4). Moreover, with the fraction of each

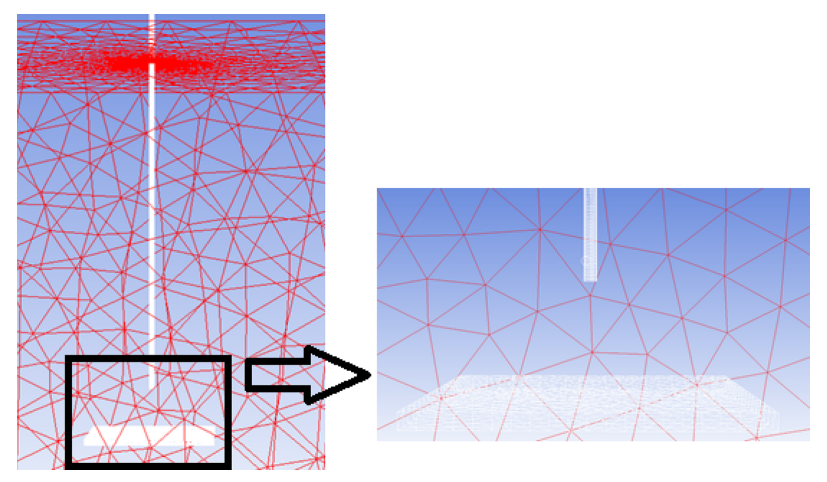

FIG. B1: CAP jet composition using 3D ANSYS Fluent analysis 
TABLE B1: Composition of the plasma jet, with relative fractions of various species at the steady state

\begin{tabular}{|c|c|}
\hline Species & Fraction \\
\hline $\mathrm{N}_{2}$ & $69.71 \%$ \\
\hline $\mathrm{O}_{2}$ & $16.29 \%$ \\
\hline $\mathrm{He}$ & $13.83 \%$ \\
\hline $\mathrm{CO}_{2}$ & $0.17 \%$ \\
\hline
\end{tabular}

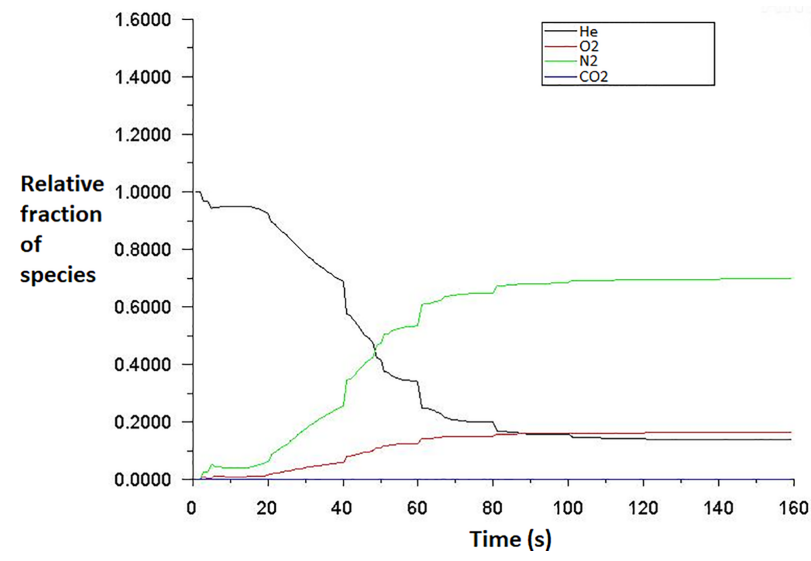

FIG. B2: Simulation by ANSYS for CAP jet composition showing fraction of each species as a function of time

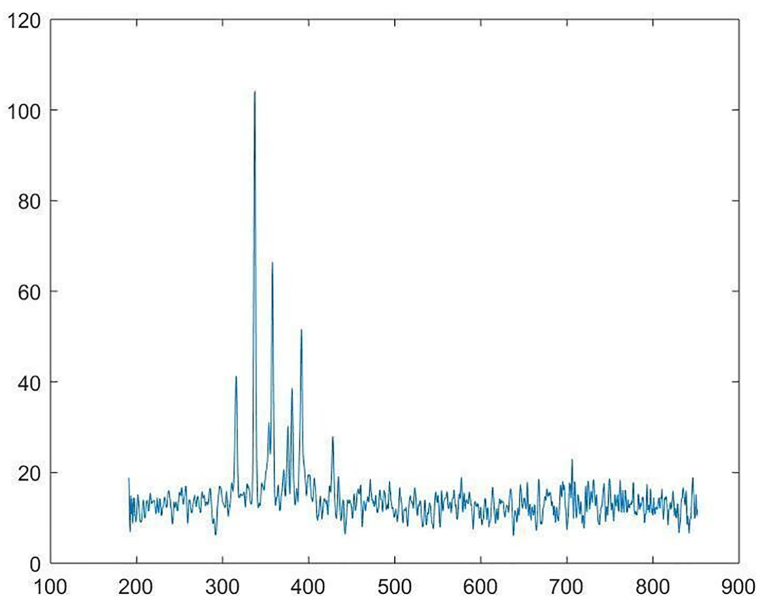

FIG. B3: Spectrum of helium plasma jet interacting with ambient air at the bottom of the jet (5 $\mathrm{cm}$ from the nozzle) 


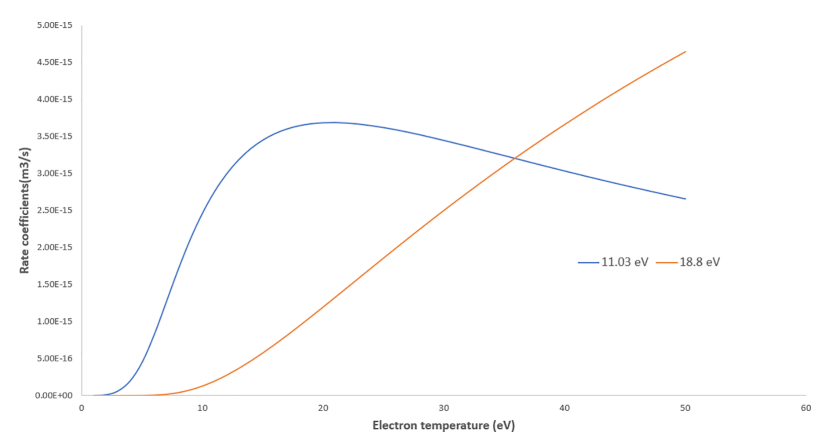

FIG. B4: Resulting rate coefficients of electron impact excitations calculated using BOLSIG+

species at the tip of plasma jet, resulting rate coefficients versus electron temperature (Fig. B4) and electron temperature versus $E / N(\mathrm{Td})$ were both calculated using BOLSIG+ (Fig. B5). After that, the relationship between $R_{k_{391} / k_{337}}\left(T_{e}\right)$ and $E / N(\mathrm{Td})$ could be estimated and is shown in Fig. B6.

After we performed a polynomial fitting of Fig. B6, we placed the value of $R_{k_{391} / k_{337}}\left(T_{e}\right)$ into the polynomial fitted equation in Fig. B6. The reduced electric field was found to be $525 \mathrm{Td}$. Then, electric field was calculated as $1.37 \times 10^{7} \mathrm{~V} / \mathrm{m}$. Therefore, the power of the plasma jet at the tip was estimated as $6.43 \mathrm{~W}$. However, the plasma discharge period is $80 \mu \mathrm{s}$, and streamer propagation only takes $\sim 2 \mu \mathrm{s}$. We assume that plasma energy was only delivered to the cells during the streamer propagation period. Therefore, the actual power of the plasma jet was calculated to be $6.43 \mathrm{~W} \times(2 / 80 \mu \mathrm{s})$ $=0.16 \mathrm{~W} \cdot{ }^{30}$

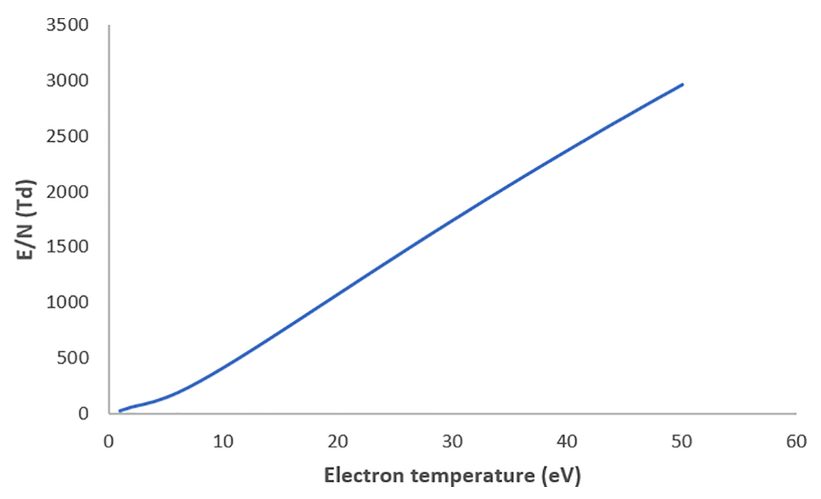

FIG. B5: $E / N(\mathrm{Td})$ versus electron temperature $(\mathrm{eV})$ 


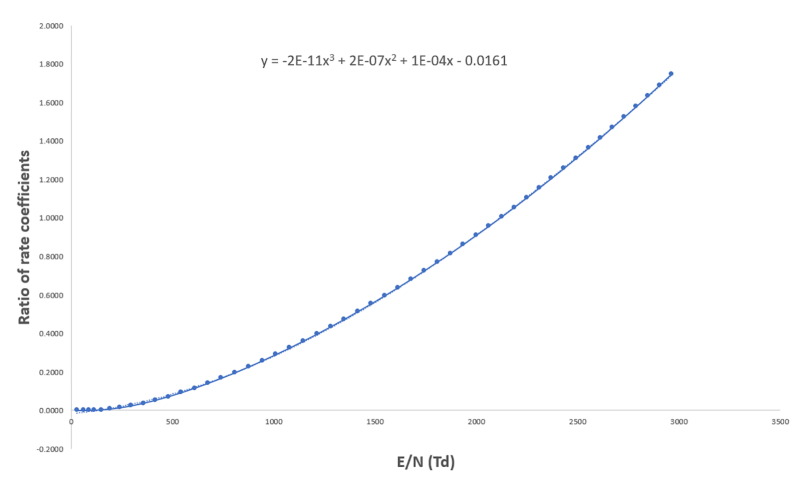

FIG. B6: Ratio of coefficients of electron impact excitations versus $E / N(T d)$

\section{APPENDIX C. TOXICITY OF TTFIELDS-TREATED DMEM}

Two samples were used for this experiment. Sample 1 was the control, with cells $(1.8 \times$ $10^{4}$ per well) cultured in DMEM overnight and replaced with $1.5 \mathrm{~mL}$ of fresh medium. Subsequently, cells were plasma treated. For sample 2, cells $\left(1.8 \times 10^{4}\right.$ per well $)$ were also cultured in DMEM overnight and replaced with fresh medium. Then, they were treated by electromotive force (EMF) for 1, 2, 3, and $4 \mathrm{~h}$ using $200 \mathrm{kHz}$ frequency with dose rates of $1,2,5,10,15$, and $19 \mathrm{~V}$ at room temperature.

It was necessary to test whether any ongoing transformation occurred that formed toxic substances by using only EMF through the electrodes to treat DMEM. Therefore, we developed an experiment to treat only the DMEM by using the EMF with $19 \mathrm{~V}$ at a frequency of $200 \mathrm{kHz}$ for $4 \mathrm{~h}$. And then we used the treated DMEM to culture cancer cells. Afterward, we compared the cell number with the untreated DMEM, and the result is shown in Fig. C1. It shows that the EMF-treated DMEM was not toxic to the U87 cells used in this experiment.

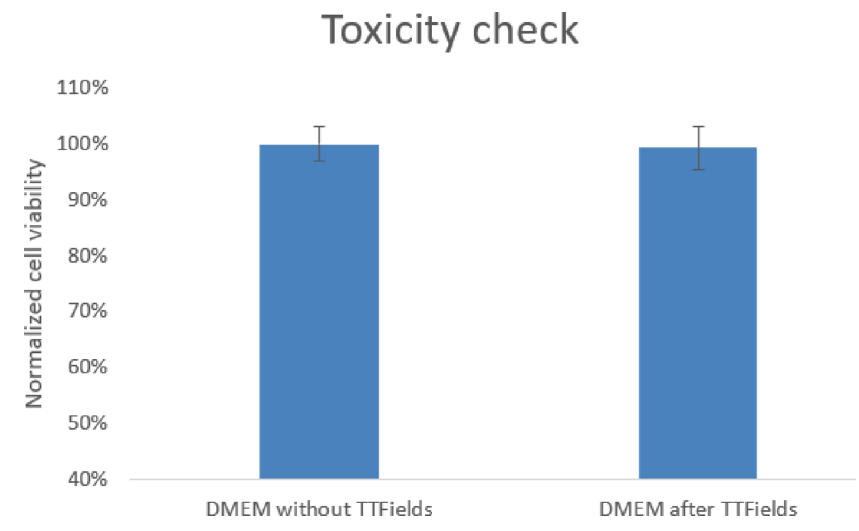

FIG. C1: Result of toxicity check 


\section{APPENDIX D. TEMPERATURE CHANGE DURING TTFIELDS TREATMENT}

Temperature could present another problem, causing inhibition of cell growth when temperature was $>43^{\circ} \mathrm{C} .{ }^{31,32}$ Temperature was measured before the TTFields experiment, at 2 and $4 \mathrm{~h}$ of the experiment. This tracking did not detect any temperature change through the course of the experiment. As result, it can be concluded that the antitumor effect of TTFields is not caused by temperature difference if voltage is $<19 \mathrm{~V}$. 
